\title{
An Improved Inverse-Time Over-Current Protection Method for a Microgrid with Optimized Acceleration and Coordination
}

\author{
Liang Ji ${ }^{1}$, Zhe Cao ${ }^{2}$, Qiteng Hong ${ }^{3}$, Xiao Chang ${ }^{4}$, Yang Fu ${ }^{1, *}$, Jiabing Shi ${ }^{5}$, Yang $\mathrm{Mi}^{1}$ and \\ Zhenkun Li ${ }^{1}$ \\ 1 School of Electrical Engineering, Shanghai University of Electric Power, Shanghai 200090, China; \\ jiliang@shiep.edu.cn (L.J.); miyang@shiep.edu.cn (Y.M.); lizhenkun@shiep.edu.cn (Z.L.) \\ 2 State Grid Fengyang County Power Supply Company, Fengyang 233100, China; shdldxcaozhe@163.com \\ 3 Department of Electronic and Electrical Engineering, University of Strathclyde, Glasgow G1 1RD, UK; \\ q.hong@strath.ac.uk \\ 4 State Grid Shanxi Electric Power Research Institute, Shanxi 030001, China; changxiao@sx.sgcc.com.cn \\ 5 State Grid Shanghai Qingpu Power Supply Company, Shanghai 200090, China; shdlsjb@163.com \\ * Correspondence: fuyang@shiep.edu.cn
}

Received: 30 August 2020; Accepted: 24 October 2020; Published: 2 November 2020

\begin{abstract}
This paper presents an improved inverse-time over-current protection method based on the compound fault acceleration factor and the beetle antennae search (BAS) optimization method for a microgrid. The proposed method can not only significantly increase the operation speed of the inverse-time over-current protection but also improve the protection coordination by considering the possible influential factors in terms of microgrid operation modes, distributed generation (DG) integration status, fault types, and positions, which are marked as the most challenging problems for over-current protection of a microgrid. In this paper, a new Time Dial Setting (TDS) of inverse-time protection is developed by applying a compound fault acceleration factor, which can notably accelerate the speed of protection by using low-voltage and short-circuit impedance during the fault. In order to improve the protection coordination, the BAS algorithm is then used to optimize the protection parameters of the pick-up current, TDS, and the inverse time curve shape coefficient. Finally, case studies and various evaluations based on DIgSILENT/Power Factory are carried out to illustrate the effectiveness of the proposed method.
\end{abstract}

Keywords: microgrid; distributed generation; inverse-time over-current protection; coordination optimization

\section{Introduction}

Nowadays, with the increasing demand for electric energy, distributed generations (DGs), such as photovoltaics, wind turbines, and fuel cells, play significant roles in power systems [1,2]. Since the DG in the microgrid is close to the load, the line loss is reduced and the energy efficiency is improved, which makes a great contribution to the reduction of carbon dioxide emissions in the world $[3,4]$. As the majority of DGs are connected to the grid via power electronic inverters, which is called inverter-interfaced DG (IIDG), new challenges have risen in energy management, planning, and design, as well as control and protection. Effective microgrid protection is the primary prerequisite for the reliable operation of a microgrid $[5,6]$.

Considering the unique fault characteristics, the conventional protection methods used in distribution systems are considered no longer sufficiently effective [7]. Firstly, the fault current level is strict by the current limiter of the inverter, which introduces challenges to the majority of conventional 
current-based protection methods [8]. Secondly, a microgrid has two different operational modes, i.e., a grid-connected mode and islanding mode, which causes notably different fault levels [9]. Thirdly, as microgrids can have multiple DGs, the fault current direction may be changed, which brings difficulties in the relay setting and coordination [10]. Furthermore, the inverter control methods alter the relationship of the output voltage and current compared with the synchronous generator and inherently increases the risk of compromising the performance of the conventional protection method [11].

Many researchers have put forward efforts to improve the performance of the microgrid protection system. Some of them focus on protection with the communication channel $[12,13]$. Slemaisardoo et al. [12] proposed a differential protection method using a non-nominal frequency current during the fault, which can better detect the microgrid fault than conventional over-current protection. Aghdam et al. [13] proposed a differential protection method based on variable tripping times, and a multi-agent protection scheme was designed to improve the coordination of adjacent relays. Except for differential protection, some papers [14-16] used the data from multiple measurement points to classify and optimize the corresponding protection parameters based on the state change of the microgrid topology and DGs. Communication-based methods are reasonable solutions for microgrid protection. However, the reliability of this type of protection highly relies on the communication facilities and performance; also, it is not an economic solution.

Some research focused on protection methods that do not rely on communication. In [17], a new directional relay using amplitude and phase of sequence components in the network is proposed. In [18], a new zero-sequence direction protection for microgrid ground faults is proposed. Huang et al. [19] proposed an inverse-time impedance protection method, which is not affected by changes in the microgrid short-circuit level. In [20], an adaptive distance protection method based on the auxiliary coefficient is proposed to solve the influence of DG on the measured impedance of the relay. Some researchers proposed improved over-current protection methods by considering the fault characteristics of the microgrid [21-23]. Muda and Jena [21] proposed an adaptive over-current protection method by increasing the fault current during the fault. The superposition current of both the positive and negative sequences was applied to amplify the value of the fault current. In [22], an adaptive over-current protection method that diagnosed the microgrid operating mode from the voltage analysis is proposed. El-Naily et al. [23] designed a new pickup current constraint based on the influence of DG on over-current protection so as to overcome the low-fault-level problem. Besides, some papers proposed methods using fault current limiters (FCLs) to limit the short-circuit level of the microgrid [24,25]. In [24], FCLs are used to limit the fault current contribution of the main grid, and the genetic algorithm is used to solve the optimal coordination of the protection. In [25], a new hybrid method that combined the Cuckoo optimization algorithm and linear programming (COA-LP) was applied to solve the coordination of the microgrid protection. Although the use of FCLs can ensure the reliability and selectivity of traditional over-current protection, the investment of additional equipment increases the cost of protection and lacks economic efficiency.

With the development of artificial intelligence technology, some smart protection methods were also developed in recent years [26-28]. Kar et al. [26] proposed a differential protection scheme based on data mining to adapt to the operating mode and topology changes of the microgrid. In [27], an adaptive protection scheme based on machine learning was proposed, which can adaptively modify the protection parameters for different operating conditions. Mishra and Rout [28] proposes a differential protection scheme based on Hilbert-Huang transform (HHT) and machine learning, in which HHT was used for feature extraction and machine learning used to classify the fault. These methods can effectively solve the relay setting and coordination problems, but the reliability and fastness of some smart algorithms are difficult to guarantee.

Although massive smart and sophisticated protection methods have been developed, the simple over-current relay (OCR), which has the characteristics of good performance, simple principles, and a low cost, is still widely used in low-voltage power grids. In practice, a lot of existing microgrid projects 
utilize the over-current relay as their main and backup protection methods [29]. However, some challenges are still not overcome. Firstly, the over-current relays utilized in a microgrid are mainly time-inverse over-current relays, the operation time of which is inversely proportioned to the fault current. Due to the low fault-current level of the microgrid, the operational speed of this type of relay is difficult to be satisfactory. Secondly, a microgrid typically has multiple DGs located in different branches, which may bring difficulty in relay coordination. Furthermore, the alteration of the operation modes of the microgrid will notably change the fault level and challenge the relay settings.

Therefore, to overcome the limitations of the conventional over-current protection methods discussed above, this paper proposes an improved inverse-time over-current (I-ITOC) protection method. A compound fault acceleration factor based on low voltage and the measured impedance was developed to improve the speed of the relay. Then, the coordination of protection is optimized by using the beetle antenna search (BAS) algorithm. Compared with the conventional over-current method, the proposed method notably improves the operation speed. Furthermore, as the proposed method does not require extra devices, it is potentially more economic and easier to implement in the field.

The rest of the paper is organized as follows: In Section 2, the compound fault acceleration factor and the I-ITOC protection method are explained. The optimal configuration of the protection parameters is described in Section 3, and case studies with simulation comparison analyses are presented in Section 4.

\section{Improved Inverse-Time Over-Current Protection Method Based on the Compound Fault Acceleration Factor}

\subsection{Introduction to the Inverse-Time Over-Current Relay}

The inverse-time over-current relay (ITOCR) has the ability to reflect the severity of faults, and its operation time is inversely proportioned to the fault current. According to the standard IEC 60255 [30], the operation characteristic equation of the ITOCR is defined as follows:

$$
t=\frac{A}{\left(\frac{I_{f}}{I_{p}}\right)^{\alpha}-1} \times \mathrm{TDS}
$$

where $t$ is the relay's operation time, $A$ is the constant coefficient, $\alpha$ is the inverse-time curve shape coefficient, $I_{f}$ is the magnitude of the fault current measured by the relay, Time Dial Setting (TDS) is the time dial setting, and $I_{p}$ is the setting of the relay's pickup current.

However, due to the changes in the operating mode of the microgrid, the limitations of the power electronics in contributing to the fault current in the microgrid, and the significant impact of the DGs' control strategy and capacity on the fault output current, there are significant differences in fault current values in the microgrid under different modes. Since the operation time of a conventional ITOCR is closely related to the fault current, the large variations in fault level will significantly affect the performance of the conventional ITOCR. Therefore, in order to ensure the satisfactory speed of the ITOCR in different modes of the microgrid, it is necessary to improve the conventional ITOC protection method.

\subsection{Development of the Compound Fault Acceleration Factor for Over-Current Protection of a Microgrid}

When the microgrid is operating in the grid-connected mode, the bus voltage and frequency are regulated by the upstream main grid. When the microgrid is switched to the islanded mode, one or some main DGs will be used to maintain the bus voltage and frequency stability. In the event of a fault, the closer the fault point is to the relay installation point, the more serious the voltage drop of the relay will be. Thus, the voltage drop of the relays can reflect the distance from the fault point to the installation of the relay. 
As shown in Figure 1, when one fault occurs downstream of the relay R2 (point $f$ ), constructing the coefficient of the fault voltage based on the characteristics of the bus fault voltage, and the fault voltage coefficient $U_{i}^{*}$ of the relay $R i$, can be defined in Equation (2):

$$
U_{i}^{*}=1-\left|\frac{U_{i}^{\text {fault }}-U_{i}^{\text {prefault }}}{U_{i}^{\text {prefault }}}\right|
$$

where $U_{i}^{\text {prefault }}$ and $U_{i}^{\text {fault }}$ are the pre-fault voltage and the fault voltage to the relay $R i$, respectively. The fault position on the line influences the value of $U_{i}^{*}$. The closer the relay is to the point of fault, the smaller $U_{i}^{*}$ is, and $U_{i}^{*}$ is less than 1 for all possible scenarios.

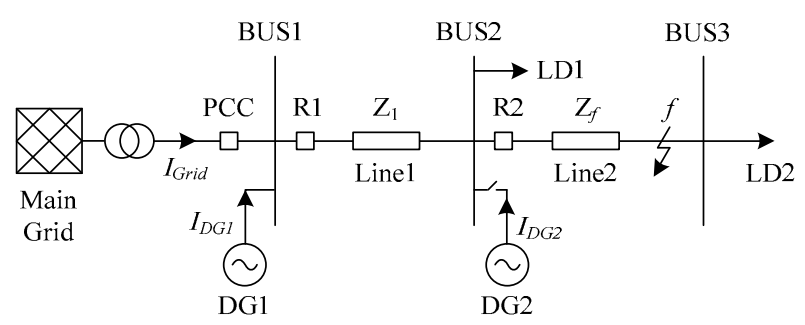

Figure 1. Simplified microgrid model.

In addition, according to the principle of distance protection, the measured impedance of the relay reflects the distance between the relay and the point of fault, and the fault impedance coefficient $Z_{i}^{*}$ can be constructed as follows:

$$
Z_{i}^{*}=\frac{\left|Z_{L}\right|}{\left|Z_{R i}\right|}
$$

where $Z_{L}$ is the line impedance, which is the total impedance between the bus PCC (BUS1) to the end of the branch (BUS3). $Z_{R i}$ is the measured impedance of the relay Ri. Please note that calculation of $Z_{R i}$ changes with different fault types; also, the closer the relay is to the point of fault, the larger the fault impedance coefficient $Z_{i}^{*}$ is. $Z_{i}^{*}$ is greater than 1 for all possible scenarios.

By combing Equations (2) and (3), the operation characteristic equation and new TDS of the I-ITOC protection method is obtained in (4) and (5), where $M_{i}$ in (6) represents the compound fault acceleration factor.

$$
\begin{gathered}
t_{i}=\frac{A}{\left(\frac{I_{f \cdot i}}{I_{p \cdot i}}\right)^{\alpha_{i}}-1} \times \operatorname{TDS}_{i}^{*} \\
\operatorname{TDS}_{i}^{*}=\operatorname{TDS}_{i} \times M_{i} \\
M_{i}=\frac{U_{i}^{*}}{Z_{i}^{*}}
\end{gathered}
$$

Compared with the conventional ITOCR, the speed of the improved inverse-time over-current relay (ITOCR) can be improved as $M_{i}$ is less than 1 for the majority of scenarios. The following section, Section 2.3, will discuss a few scenarios in which $M_{i}$ is greater than 1 . In the case of the islanded mode of the microgrid, due to the influence of the DG capacity, the DG's maintain bus voltage capability is weaker than that of the main grid. Therefore, the compound fault acceleration factor $M_{i}$ in the islanded mode is smaller than that of the grid-connected mode. Inherently, the influence of a low fault level on the protection operation time during the island mode can be further reduced.

\subsection{Effect of DG on the Compound Fault Acceleration Factor}

The presence of DGs in the microgrid can change the fault current flowing through the relay, which will result in a different operation time by applying the ITOC. Besides, the fault current of the 
DG may also affect the fault measurement impedance of the backup relay. In Figure 1, when a fault occurs downstream of the relay R2, the impedance measured by the relays R1 and R2 can be obtained by Equations (7) and (8):

$$
\begin{gathered}
Z_{R 1}=Z_{1}+Z_{f}+Z_{D G}^{*} \\
Z_{R 2}=Z_{f}
\end{gathered}
$$

where

$$
Z_{D G}^{*}=\frac{I_{D G 2}}{I_{B U S 1}} \times Z_{f}
$$

In Equations (7) and (8), $Z_{R 1}$ and $Z_{R 2}$ are the measured impedance of the relay $R 1$ and $R 2, Z_{f}$ is the impedance between relay R2 and fault point $f$, and $Z_{D G}^{*}$ is the contribution impedance of DG2's fault current to relay R1. In Equation (9), $I_{B U S 1}$ is the fault current flowing through BUS1 and $I_{D G 2}$ is the fault current of the DG2.

When the fault occurs in the grid-connected mode, $I_{B U S 1}$ will typically be much greater than $I_{D G 2}$, and $Z_{D G}^{*}$ can be ignored. When the fault occurs in the microgrid islanded mode, the magnitude of $\left|I_{D G 2} / I_{B U S 1}\right|$ is affected by the DG control strategy and the severity of the fault. Since the phase angle of $\left|I_{D G 2} / I_{B U S 1}\right|$ is between $-90^{\circ}$ and $90^{\circ}[19], Z_{R 1}$ is still greater than $Z_{R 2}$, and the fault impedance coefficient $Z_{1}^{*}$ and $Z_{2}^{*}$ measured by the relays $R 1$ and $R 2$ still satisfies the criteria that $Z_{2}^{*}$ is greater than $Z_{1}^{*}$.

However, when the capacity of the DG is relatively large, the fault current of the DG may cause may cause the protection measurement impedance $Z_{R i}$ to be greater than the set impedance $Z_{L}$, inherently affecting the speed of the protection. Therefore, the compound fault acceleration factor $M_{i}$ and the I-ITOC protection method is improved, which can be expressed in Equations (10) and (11).

$$
M_{i}=\frac{U_{i}^{*}}{1+Z_{i}^{*}}
$$

where

$$
Z_{i}^{*}= \begin{cases}1 & Z_{i}^{*}<1 \\ \left|Z_{L} / Z_{R i}\right| & Z_{i}^{*} \geq 1\end{cases}
$$

In order to maintain the acceleration effect of $M_{i}$ when the contribution of DG to the protection measurement impedance is too large, the denominator of $M_{i}$ is changed, and 1 is taken when the fault impedance coefficient $Z_{i}^{*}$ is less than 1 .

\section{Protection Coordination Optimization Based on the Beetle Antennae Search Algorithm}

Due to the unique fault characteristics in the microgrids and the influence of the DG, the conventional settings of the ITOCR cannot be directly applied for effective microgrid protection. Figure $2 \mathrm{a}, \mathrm{b}$ are the protection operation characteristics curve of the conventional ITOCR under different operation modes of the microgrid.

As shown in Figure 2a, if the settings are configured based on the grid-connected operational mode, the speed of the relay in the islanded mode could be too slow due to the reduced fault level; as shown in Figure $2 b$, if the settings are calculated based on the islanded operational mode, the coordination time interval (CTI) of the adjacent relays in the grid-connected mode could be too small to ensure the coordination of protection. In addition, the contribution of the DG to the fault current flowing through the relay also affects the coordination of the relay. Therefore, in order to ensure the selectivity and speed of I-ITOCR in different operation modes of the microgrid, it is necessary to optimize the parameters of each relay. 


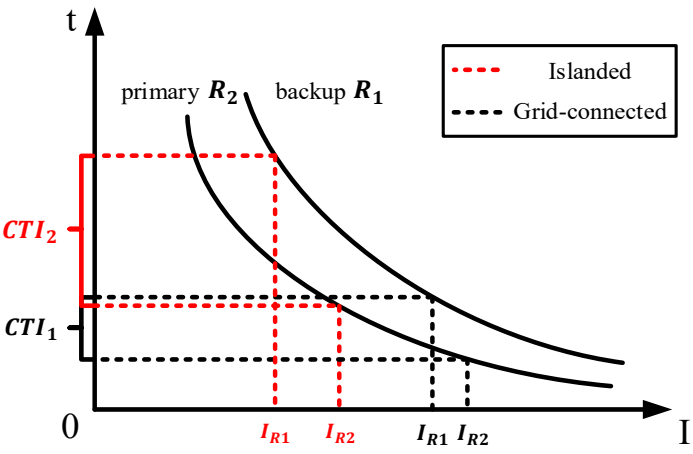

(a)

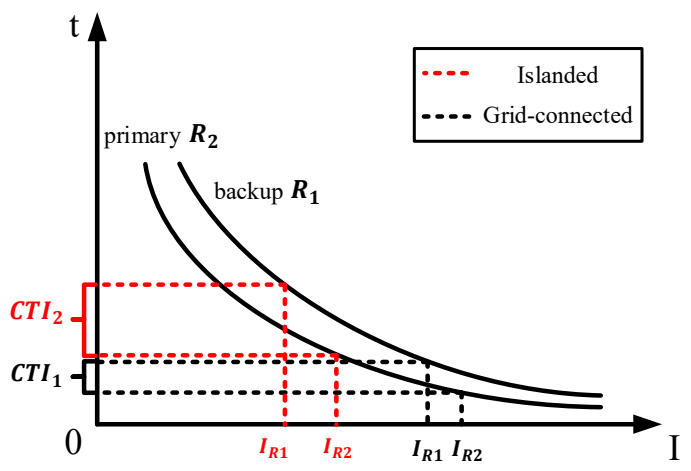

(b)

Figure 2. Operation time in different modes of the microgrid: (a) Parameters are set according to the grid-connected mode; (b) parameters are set according to the islanded mode.

\subsection{Coordinated Optimization of the I-ITOCRs}

The I-ITOCR operating characteristic equation is shown in Equation (6). In general, parameters A and $\alpha$ are fixed for a certain relay and the parameters $I_{p \cdot i}$ and $T D S_{i}$ need to be set. In this paper, in order to reduce the impact of current changes and achieve optimal coordination, the index $\alpha_{i}$ is also added as the optimization variable. The objective function of the optimization problem is formulated in Equation (12), which represents the sum of the operation time for I-IOCR considering both the grid-connected and islanded operation modes of the microgrid.

$$
\underset{I_{p}, \alpha, T D S}{\operatorname{Min}} \mathrm{F}=\sum_{m=1}^{2} \sum_{n=1}^{4}\left(\sum_{k=1}^{K}\left(t_{p r \cdot k}^{i}+\sum_{j=1}^{2} t_{b c \cdot k}^{i j}\right)\right)
$$

where $m$ denotes the operation mode of the microgrid, and the numbers 1 and 2, respectively, indicate the grid-connected and islanded modes of the microgrid; $n$ represents different fault types; $k$ represents the different fault conditions, here being the first and end fault of each line; $i$ represents the primary relay and $j$ represents the backup relay to the primary relay $I$; and $t$ denotes the operation time of the relays, with $t_{p r \cdot k}^{i}$ denoting the operation time of the primary relay and $t_{b c \cdot k}^{i j}$ denoting the operation time of the backup relay.

The total operation time of the I-IOCRs is reduced by obeying their constraints as follows.

\subsubsection{Protection Coordination Constraints}

When a fault occurs in the network, in order to ensure the selectivity of the relay, there should be a reasonable CTI between the backup and primary relay operation time and this relationship also exists between the remaining protection and backup protection operation time. The CTI can be expressed as Equations (13) and (14):

$$
\begin{aligned}
& C T I_{i \cdot 1}=t_{b c \cdot k}^{i 1}-t_{p r \cdot k}^{i} \\
& C T I_{i \cdot 2}=t_{b c \cdot k}^{i 2}-t_{b c \cdot k}^{i 1}
\end{aligned}
$$

The CTI should have a minimum value by considering the operation time of the circuit breaker and a safety margin, where an excessive CTI is unfavorable to the stability of the system [31]. Therefore, the $C T I_{i \cdot 1}$ is limited to between 0.2 and 0.5 , and the $C T I_{i \cdot 2}$ is greater than 0.2 [32]. It can be represented as follows:

$$
\begin{gathered}
C T I_{\min } \leq C T I_{i \cdot 1} \leq C T I_{\max } \\
C T I_{\min } \leq C T I_{i \cdot 2}
\end{gathered}
$$




\subsubsection{Protection Operation Time Constraint}

Considering the speed of the relay and the stability of the system, the maximum and minimum operation time of the relay must be limited. For all the I-ITOCRs, the protection operation time is set between 0 and $2 \mathrm{~s}$. The limit of the protection operation time is as shown in Equations (17) and (18):

$$
\begin{aligned}
& t_{\min } \leq t_{p r \cdot k}^{i} \leq t_{\max } \\
& t_{\min } \leq t_{b c \cdot k}^{i j} \leq t_{\max }
\end{aligned}
$$

\subsubsection{Protection Parameter Constraint}

In this part, the constraint of the pickup current $I_{p \cdot i}$, the Time Dial Setting $T D S_{i}$, and the index $\alpha_{i}$ are introduced.

The range of values for each relay's pickup current is determined by the network. According to the requirements of the IEC standard, the pickup current must be greater than the maximum load current $I_{L \cdot \max }$ of the line, which is normally set as $I_{p \cdot i}>1.1 I_{L \cdot \max }$ [23]. In order to ensure the reliability of the protection, the pickup current must be smaller than the minimum fault current $I_{f \cdot m i n}$, which is the fault current of the two-phase fault at the remote end of the feeder. The $T D S_{i}$ is generally set between 0.05 and $11 \mathrm{~s} \mathrm{[33].} \mathrm{According} \mathrm{to} \mathrm{Standard} \mathrm{IEC} \mathrm{60255,} \mathrm{the} \mathrm{inverse} \mathrm{time} \mathrm{type} \alpha_{i}$ is usually between 0.02 and 13.5 [34]. Finally, the lower and upper bounds of the I-ITOCR's parameters are given in (19)-(21).

$$
\begin{gathered}
\alpha_{\min }<\alpha_{i}<\alpha_{\max } \\
I_{p}^{\min } \leq I_{p \cdot i} \leq I_{p}^{\max } \\
T D S_{\min } \leq T D S_{i} \leq T D S_{\max }
\end{gathered}
$$

\subsection{Parameter Optimization of the I-ITOCR Based on the Beetle Antenna Search Algorithm}

According to the microgrid network structure and the fault condition, the objective function (12) and the constraints (13)-(16) can be obtained. Next, considering the constraints (17)-(21) of the parameter variables, the optimal parameter configuration for each relay can be determined. Since the above problem is a nonlinear optimization problem, the solving process is complicated and difficult. Therefore, in this section, the BAS algorithm is used to solve this nonlinear optimization problem to obtain the optimal configuration of the I-ITOCR's parameters.

The BAS algorithm is a meta-heuristic algorithm for multi-objective function optimization, which imitates the perception function of beetle antennae to judge the fitness of local areas around itself and guides individuals to move to the global optimal solution through the optimal solution of local areas [35]. Compared with the particle swarm optimization algorithm, the BAS algorithm only needs one individual, which greatly reduces the computational complexity.

The algorithm flow of the BAS is shown in Figure 3, and its main steps are explained as follows:

Step 1: Randomly generate the direction vector $\vec{b}$ of the beetle antennae and normalize it.

$$
\vec{b}=\frac{\operatorname{rands}(\mathrm{g}, 1)}{\|\operatorname{rands}(\mathrm{g}, 1)\|}
$$

where rands denotes a random function and $g$ presents the dimensions of the position. Here, the size of $g$ is related to the number of relays to be optimized.

Step 2: Calculate the left and right spatial coordinates $X_{l}$ and $X_{r}$ of the antennae according to the initial search distance $d^{t}$ and $\vec{b}$.

$$
X_{l}=X^{t}-d^{t} \vec{b}
$$




$$
X_{\mathrm{r}}=X^{t}+d^{t} \vec{b}
$$

where $X^{t}$ is the position of the beetle at the $t^{\text {th }}$ iteration, and $X^{t}$ can be expressed as Equation (25):

$$
X^{t}=\left[I_{p \cdot 1}^{t}, \alpha_{1}^{t}, \operatorname{TDS}_{1}^{t}, \cdots, I_{p \cdot w}^{t}, \alpha_{w}^{t}, \operatorname{TDS}_{w}^{t}\right]^{T}
$$

where $w$ is the number of relays to optimize.

Step 3: Calculate the odor intensity $f\left(X_{l}\right)$ and $f\left(X_{r}\right)$ based on the spatial coordinates and the fitness function $f(X)$.

$$
\begin{aligned}
& f\left(X_{l}\right)=F\left(X_{l}\right) \\
& f\left(X_{r}\right)=F\left(X_{r}\right)
\end{aligned}
$$

where $F($.$) is the objective function shown in Equation (12).$

Step 4: Determine the position $x^{t+1}$ of the next moment of the beetle according to the fitness function value.

$$
X^{t+1}=X^{t}-\delta^{t} \vec{b} \operatorname{sign}\left(f\left(X_{l}\right)-f\left(X_{r}\right)\right)
$$

where $\delta^{t}$ represents the step size and sign(.) represents a sign function.

Step 5: Update the step size $\delta^{t}$ and search distance $d^{t}$.

Step 6: Iterate to the maximum number of iterations and output the result.

Through the above steps, the optimal parameters $I_{p \cdot i}, T D S_{i}$, and $\alpha_{i}$ of each relay in the microgrid can be obtained, and the coordination problem of the microgrid protection can be solved.

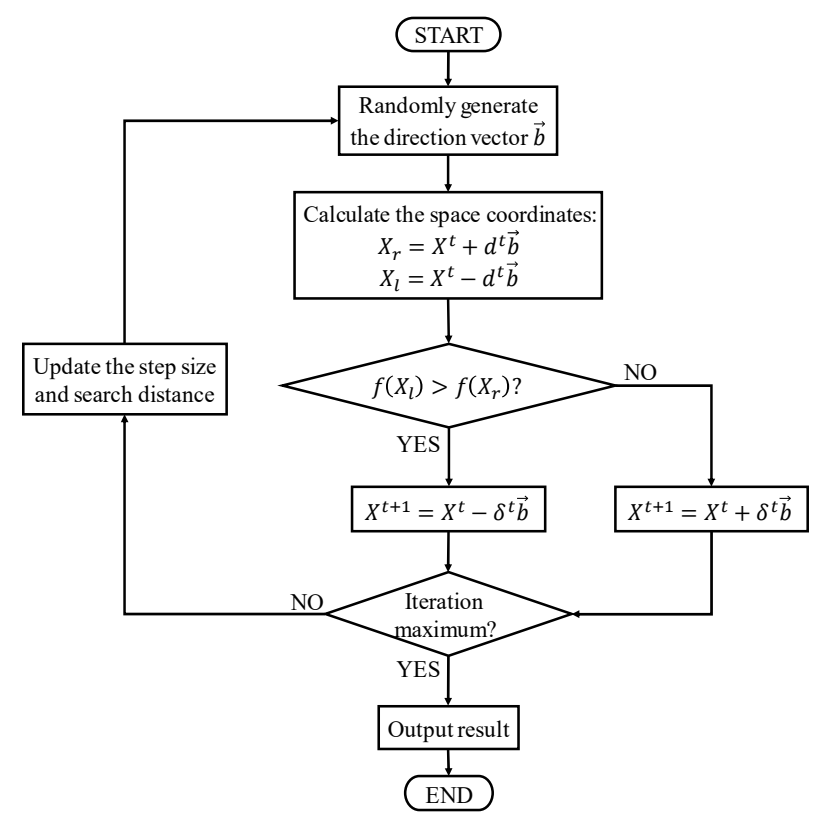

Figure 3. Flowchart of the beetle antenna search (BAS) algorithm.

\subsection{Classification of Microgrid Scenarios Based on DG Status}

Since the connection status of the DG in the microgrid affects the fault current in the network, it is necessary to classify the scenarios of the microgrid according to whether the DG is connected and obtain the optimal protection parameters under the corresponding scenarios. Please note that the information about the connection status of DG can be obtained from the central controller of the microgrid in practice [23].

Figure 4 shows a typical microgrid structure which contains 4 DGs and two branches. The classification of the microgrid scenarios follows the following criteria. First of all, it is not necessary 
to consider the PCC connection status, because the parameter optimization can comprehensively consider the microgrid operation modes, i.e., the grid-connected and islanded mode. Secondly, during the microgrid grid-connect operation mode, DGs apply conventional PQ control. During the microgrid island operation mode, the widely used master-slave control strategy is applied. DG1, which is assumed as a stable resource, is chosen as the unit to maintain the microgrid voltage and frequency. Finally, the scenarios of the microgrid are classified according to the state changes of the remaining DGs.

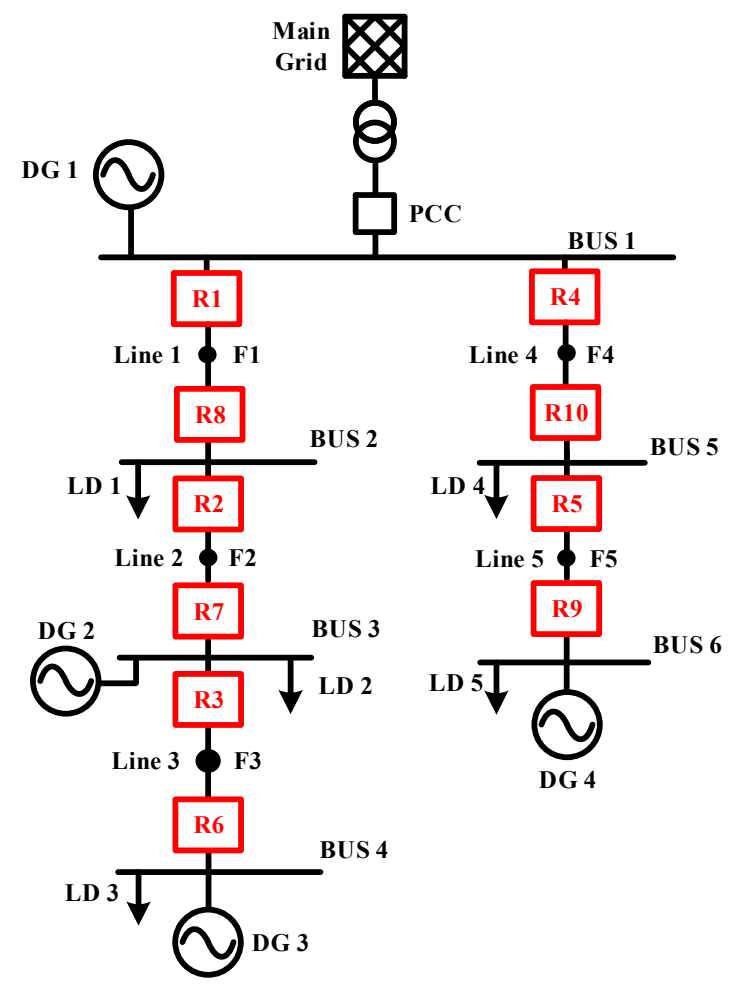

Figure 4. Schematic diagram of the microgrid.

According to the above classification principle, the microgrid network shown in Figure 4 can be divided into eight scenarios, as shown in Table 1. Relays R1-R10 are directional over-current relays. In different modes of the microgrid, the fault currents flowing through Relays R1, R2, R3, R4, and R5 are obviously different. It is necessary to optimize the parameters according to the above optimization process. The fault current flowing through Relays R6, R7, R8, R9, and R10 is less affected by the change in the operating mode of the microgrid, and the parameters can be configured according to the conventional protection method, which is beyond the scope of this paper.

Table 1. Scenarios classification of the microgrid.

\begin{tabular}{cccc}
\hline Scenarios & DG2 & DG3 & DG4 \\
\hline 1 & OFF & OFF & OFF \\
2 & ON & ON & OFF \\
3 & ON & OFF & ON \\
4 & ON & OFF & OFF \\
5 & OFF & OFF & ON \\
6 & OFF & ON & OFF \\
7 & OFF & ON & ON \\
8 & ON & ON & ON \\
\hline
\end{tabular}




\section{Simulation Results}

The proposed method based on the compound acceleration factor and BAS optimization algorithm aim to improve the speed and coordination of the microgrid protection. The impacts of negative factors on the conventional ITOCR in terms of a low fault level, microgrid operation mode, DG positions, and DG integration status have been notably reduced. In this section, the speed and coordination of the proposed protection method are evaluated. The possible negative influencing factors on the performance of the proposed method, such as fault types, fault positions, and microgrid operation modes, are evaluated. Besides, the comparison between the proposed method and the conventional method is also included in this section.

In the simulation, the model of a typical microgrid shown in Figure 4 is established in DIgSILENT/Power Factory. The detailed parameters of the microgrid are shown in Table 2. All DGs adopted the PQ control during the grid-connected operation mode of the microgrid. During the islanded operation mode, the microgrid applies the master-slave control mode. DG1, which is assumed as the most stable and reliable resource in the microgrid, is denoted as the master DG and adopts the V/f control. In turn, the other DGs kept using the PQ control. The initial state of the DGs in the microgrid is Scenario 1 in Table 1. The change in DG status will be evaluated in this section. Due to the thermal limit of the power inverter, the fault current limit of the DGs is set as 2 p.u. For conventional ITOCRs, the parameters of $\mathrm{A}$ and $\alpha$ are set as 0.14 and 0.02 , and the minimum allowed CTI is set to $0.3 \mathrm{~s}$ [22,32]. F1 to F5 in Figure 4 denotes the fault positions.

Table 2. Simulation parameters of the microgrid model.

\begin{tabular}{cc}
\hline Element & Parameter \\
\hline DG1/DG2/DG3/DG4 & $1500 / 100 / 200 / 500 \mathrm{~kW}$ \\
Line Parameters and length & $0.01+\mathrm{j} 0.015 \Omega / \mathrm{km}, 1 \mathrm{~km}$ \\
Load1/Load2/Load3/Load4/Load5 & $300 / 100 / 200 / 200 / 400 \mathrm{~kW}$ \\
PCC Voltage/Frequency & $0.4 \mathrm{kV} / 50 \mathrm{~Hz}$ \\
\hline
\end{tabular}

\subsection{Optimized Configuration of the Protection Parameters}

The settings parameters of the microgrid protection of Scenario 1 are optimized based on the methods described in Section 3. Table 3 shows the optimal protection parameters obtained according to the BAS algorithm optimization process shown in Figure 3.

Table 3. Optimal configuration of the protection parameters in Scenario 1.

\begin{tabular}{cccc}
\hline Relay & $\boldsymbol{I}_{\boldsymbol{p} \cdot \boldsymbol{i}} / \mathbf{I}_{\boldsymbol{L} \cdot \boldsymbol{m a x}_{\boldsymbol{i}}}$ & TDS $_{\boldsymbol{i}}$ & $\boldsymbol{\alpha}_{\boldsymbol{i}}$ \\
\hline $\mathrm{R} 1$ & 1.1277 & 0.5061 & 0.0211 \\
$\mathrm{R} 2$ & 1.1308 & 0.7231 & 0.0201 \\
$\mathrm{R} 3$ & 1.5788 & 0.7511 & 0.0214 \\
$\mathrm{R} 4$ & 1.1105 & 8.7153 & 0.2981 \\
R5 & 2.9282 & 0.1495 & 0.0262 \\
\hline
\end{tabular}

\subsection{Evaluation of the Acceleration Capability of the Proposed Method}

In this section, the acceleration capability of the proposed method is evaluated with different microgrid operating modes, fault types, and positions, and the comparison with conventional protection methods is carried out.

\subsubsection{Evaluations in the Grid-Connected Mode of the Microgrid}

(a) Different fault positions: In this case, the simulations are performed for different fault positions in the grid-connected mode. The three-phase faults are applied in this case, while the evaluations of different fault types will be discussed in the following section. 
When fault F3 of Line 3 occurred, the fault current is measured as $5.2553 \mathrm{kA}$, and the acceleration factor $M_{i}$ is calculated to be 0.0417 according to (10). According to the protection parameters in Table 3 , the action delay of R3 is $0.0499 \mathrm{~s}$. Figure 5 shows the voltage change of the bus when occurring at F3 of Line 3. From Figure 5, it is found that the operation time of the conventional primary relay is $0.1096 \mathrm{~s}$, and the improved primary relay is $0.0597 \mathrm{~s}$ faster than the traditional relay. Table 4 shows the simulation results with different fault positions. The simulation results prove that the speed of the improved protection method can be guaranteed with different fault positions, and both the primary and backup relay's operation times of the I-ITOCR are faster than those of the ITOCR.

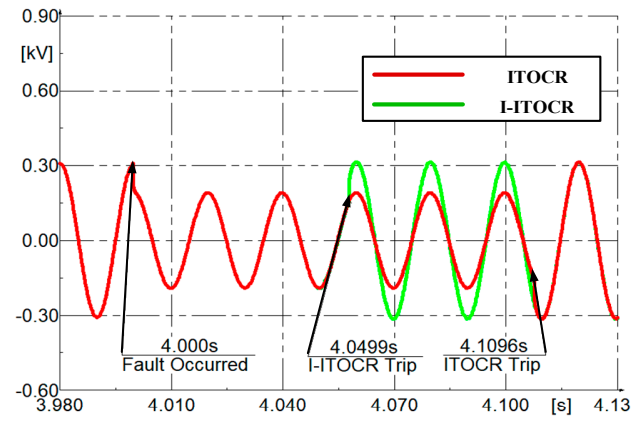

Figure 5. Bus voltage during the fault at F3.

Table 4. Operation times of the different fault positions in the grid-connected mode.

\begin{tabular}{ccccc}
\hline \multirow{2}{*}{$\begin{array}{c}\text { Fault } \\
\text { Position }\end{array}$} & \multicolumn{4}{c}{ Relay Operational Time (s) } \\
\cline { 2 - 5 } & \multicolumn{2}{c}{ I-ITOCR } & \multicolumn{2}{c}{ ITOCR } \\
\cline { 2 - 5 } & PR & BR & PR & BR \\
\hline F1 & 0.1110 & - & 0.4678 & - \\
F2 & 0.0701 & 0.4259 & 0.3549 & 0.7307 \\
F3 & 0.0499 & 0.3799 & 0.1096 & 0.4437 \\
F4 & 0.0837 & - & 0.3094 & - \\
F5 & 0.0204 & 0.3789 & 0.1179 & 0.4828 \\
\hline
\end{tabular}

Note: PR and BR represent primary relay and backup relay, respectively.

(b) Different fault types: This section evaluates the speed of the proposed protection method with different fault types in the grid-connected mode. Table 5 shows the operation times of the I-ITOCRs and ITOCRs. The fault is set at the F2 of Line 2. In the table, A, B, C, and D represent a single-phase-to-ground fault, a two-phase fault, a two-phase-to-ground fault, and three-phase fault, respectively. The operation time for the improved primary relays are all less than $0.15 \mathrm{~s}$, and the conventional primary relays are all greater than $0.35 \mathrm{~s}$, which proves that the I-ITOCR can adopt all the fault types and is faster than the ITOCRs under different fault types.

Table 5. Operation times of the different fault types in the grid-connected mode.

\begin{tabular}{ccccc}
\hline \multirow{2}{*}{$\begin{array}{c}\text { Fault } \\
\text { Type }\end{array}$} & \multicolumn{3}{c}{ Relay Operational Time (s) } \\
\cline { 2 - 5 } & \multicolumn{2}{c}{ I-ITOCR } & \multicolumn{2}{c}{ ITOCR } \\
\cline { 2 - 5 } & PR & BR & PR & BR \\
\hline A & 0.1409 & 0.5264 & 0.3556 & 0.7297 \\
B & 0.0676 & 0.4151 & 0.3729 & 0.7705 \\
C & 0.0640 & 0.3947 & 0.3552 & 0.7292 \\
D & 0.0701 & 0.4259 & 0.3549 & 0.7307 \\
\hline
\end{tabular}




\subsubsection{Evaluations in the Islanded Mode of the Microgrid}

(a) Different fault positions: This case tests the speed of the proposed protection method for different fault position in the islanded mode. Please note that the three-phase fault is included in this case; other fault types will be discussed in the following section.

When fault F3 of Line 3 occurred, the fault current is $3.1970 \mathrm{kA}$, and the acceleration factor $M_{i}$ is 0.0412 according to (10). According to the protection parameters in Table 3, the action delay of R3 is $0.0568 \mathrm{~s}$. Figure 6 shows the voltage of the I-ITOCR and ITOCR of BUS2 when a fault occurs at F3 of Line 3. As can be seen from Figure 6, the operation time of the conventional primary relay is $0.1650 \mathrm{~s}$, and the action delay of the improved primary relay is much shorter than that of the conventional protection method.

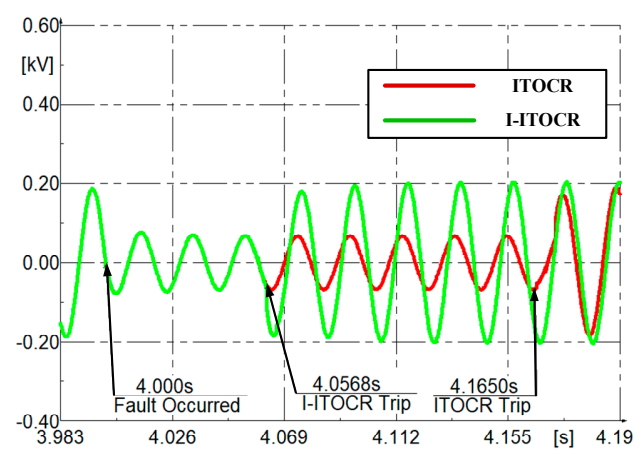

Figure 6. Bus voltage during the fault at F3.

Table 6 shows the simulation results of the other faults in this case. Note that, since the fault level of the microgrid is reduced, when the fault occurs at the F1 point, the operation time of the conventional primary relay is $1.1519 \mathrm{~s}$, and the operation time for the improved primary relay is only $0.0728 \mathrm{~s}$, which is much smaller than the conventional protection method. In addition, the primary and backup relay's operation time at other points of the I-ITOCR is also notably faster than the ITOCR. Therefore, the improved method has a better speed in the islanded mode of the microgrid.

Table 6. Operation times of the different fault positions in the islanded mode.

\begin{tabular}{ccccc}
\hline \multirow{2}{*}{$\begin{array}{c}\text { Fault } \\
\text { Position }\end{array}$} & \multicolumn{3}{c}{ Relay Operational Time (s) } \\
\cline { 2 - 5 } & \multicolumn{2}{c}{ I-ITOCR } & \multicolumn{2}{c}{ ITOCR } \\
\cline { 2 - 5 } & PR & BR & PR & BR \\
\hline F1 & 0.0728 & - & 1.1519 & - \\
F2 & 0.0667 & 0.5033 & 0.6013 & 1.5919 \\
F3 & 0.0568 & 0.4419 & 0.1650 & 0.7408 \\
F4 & 0.0715 & - & 0.7591 & - \\
F5 & 0.0389 & 0.5181 & 0.2155 & 1.0478 \\
\hline
\end{tabular}

(b) Different fault types: In this case, the speed of the improved protection method for different types of faults in the islanded mode is tested. Table 7 shows the operation times of the ITOCRs and I-ITOCRs when different types of faults occur at the F3 of Line 3 of the microgrid. As can be seen from Table 7 , the operation time for the improved primary relays are all less than $0.15 \mathrm{~s}$, and the conventional primary relays are all greater than $0.16 \mathrm{~s}$, which proves that the I-ITOCR is faster than the ITOCRs under different failure types in the islanded mode of the microgrid. 
Table 7. Operation times of the different fault types in the islanded mode.

\begin{tabular}{ccccc}
\hline \multirow{2}{*}{$\begin{array}{c}\text { Fault } \\
\text { Ttype }\end{array}$} & \multicolumn{3}{c}{ Relay Operational Time (s) } \\
\cline { 2 - 5 } & \multicolumn{2}{c}{ I-ITOCR } & \multicolumn{2}{c}{ ITOCR } \\
\cline { 2 - 5 } & PR & BR & PR & BR \\
\hline A & 0.1490 & 0.5409 & 0.1677 & 0.7508 \\
B & 0.0481 & 0.4161 & 0.1915 & 0.9061 \\
C & 0.0430 & 0.3379 & 0.1667 & 0.6681 \\
D & 0.0568 & 0.4419 & 0.1650 & 0.7408 \\
\hline
\end{tabular}

\subsection{Evaluations of Protection Coordination of the Proposed Method}

In this section, the coordination of the protection methods is evaluated via the aspects of different operating modes, fault positions and types, and DG integration status. In this simulation, the traditional protection parameters are set according to the islanded mode of the microgrid.

\subsubsection{Evaluations in the Grid-Connected Mode of the Microgrid}

(a) Different fault positions: The simulations are performed with different fault position in the grid-connected mode. The fault type in this section is set as a three-phase fault; other fault types are discussed in the following section.

Table 8 shows the simulation results of the different fault positions. From the table, it is found that the CTIs between the primary and backup relays of the conventional protection are all less than $0.195 \mathrm{~s}$, which causes the backup relay to remain active after the primary relay trips $(C T I<0.2)$. As a result, the selectivity of the protection cannot be guaranteed.

Table 8. Operation times of the different fault positions in the grid-connected mode

\begin{tabular}{ccccccc}
\hline \multirow{2}{*}{$\begin{array}{c}\text { Fault } \\
\text { Position }\end{array}$} & \multicolumn{5}{c}{ Relay Operational Time (s) } \\
\cline { 2 - 7 } & PR & BR & CTI & PR & BR & CTI \\
\cline { 2 - 7 } & 0.1110 & - & - & 0.2162 & - & - \\
F1 & 0.0701 & 0.4259 & 0.3558 & 0.2126 & 0.3377 & 0.1251 \\
F2 & 0.0499 & 0.3799 & 0.3300 & 0.0724 & 0.2658 & 0.1934 \\
F3 & 0.0837 & - & - & 0.1394 & - & - \\
F4 & 0.0204 & 0.3789 & 0.3585 & 0.0621 & 0.2175 & 0.1554 \\
F5 & $0.06 R$ &
\end{tabular}

For the proposed I-ITOCR method, the CTIs between the primary and backup relays of the improved protection method is all around $0.35 \mathrm{~s}$, which fully satisfy the coordination requirement $(0.2<C T I<0.5)$. Therefore, improved protection can ensure the selectivity for different fault positions in the grid-connected mode.

(b) Different fault types: This section evaluates the coordination of the proposed protection method for different types of faults in the grid-connected mode. Table 9 shows the operation times of the ITOCRs and I-ITOCRs with different fault types occurring at the F2 of Line 2. From the results, it is found that the CTIs of the conventional ITOCR are all less than $0.14 \mathrm{~s}$, which do not satisfy the coordination requirement $(C T I<0.2)$. In turn, the CTI of the improved I-ITOCR is all in the range $(0.2<C T I<0.5)$ for different fault types, which promises the protection coordination and selectivity. 
Table 9. Operation times of the different fault types in the grid-connected mode.

\begin{tabular}{|c|c|c|c|c|c|c|}
\hline \multirow{3}{*}{$\begin{array}{l}\text { Fault } \\
\text { Type }\end{array}$} & \multicolumn{6}{|c|}{ Relay Operational Time (s) } \\
\hline & \multicolumn{3}{|c|}{ I-ITOCR } & \multicolumn{3}{|c|}{ ITOCR } \\
\hline & PR & BR & CTI & PR & BR & CTI \\
\hline A & 0.1409 & 0.5264 & 0.3855 & 0.2131 & 0.3372 & 0.1241 \\
\hline $\mathrm{B}$ & 0.0676 & 0.4151 & 0.3475 & 0.2234 & 0.3561 & 0.1327 \\
\hline $\mathrm{C}$ & 0.0640 & 0.3947 & 0.3307 & 0.2128 & 0.3382 & 0.1254 \\
\hline $\mathrm{D}$ & 0.0701 & 0.4259 & 0.3558 & 0.2126 & 0.3377 & 0.1251 \\
\hline
\end{tabular}

\subsubsection{Evaluations in the Islanded Mode of the Microgrid}

(a) Different fault positions: In this case, the simulation is performed for different fault position in the islanded mode. Table 10 shows the simulation results of the example, and the faults are all three-phase faults; other fault types are discussed in the following section. As can be seen from the simulation results, the CTI between the primary and backup relays of the improved protection and conventional protection methods meet the condition $(0.2<C T I<0.5)$, and the selectivity of these protections is not lost for different fault position in the islanded mode.

Table 10. Operation times of the different fault positions in the islanded mode.

\begin{tabular}{|c|c|c|c|c|c|c|}
\hline \multirow{3}{*}{$\begin{array}{l}\text { Fault } \\
\text { Position }\end{array}$} & \multicolumn{6}{|c|}{ Relay Operational Time (s) } \\
\hline & \multicolumn{3}{|c|}{ I-ITOCR } & \multicolumn{3}{|c|}{ ITOCR } \\
\hline & PR & BR & CTI & PR & BR & CTI \\
\hline F1 & 0.0728 & - & - & 0.5322 & - & - \\
\hline $\mathrm{F} 2$ & 0.0667 & 0.5033 & 0.4366 & 0.3602 & 0.7355 & 0.3753 \\
\hline F3 & 0.0568 & 0.4419 & 0.3851 & 0.1088 & 0.4437 & 0.3349 \\
\hline $\mathrm{F} 4$ & 0.0715 & - & - & 0.3419 & - & - \\
\hline F5 & 0.0389 & 0.5181 & 0.4792 & 0.1135 & 0.4718 & 0.3583 \\
\hline
\end{tabular}

(b) Different fault types: This section evaluates the coordination of the proposed protection method for different types of faults in the islanded mode. Table 11 shows the operation time of ITOCRs and I-ITOCRs with different fault types occurring at the F2 of Line 2. From the results, it is found that the CTIs of the I-ITOCR and ITOCR are all in the range $(0.2<\mathrm{CTI}<0.5)$ for different fault types, which promises the protection coordination and selectivity.

Table 11. Operation times of the different fault types in the grid-connected mode.

\begin{tabular}{|c|c|c|c|c|c|c|}
\hline \multirow{3}{*}{$\begin{array}{l}\text { Fault } \\
\text { Type }\end{array}$} & \multicolumn{6}{|c|}{ Relay Operational Time (s) } \\
\hline & \multicolumn{3}{|c|}{ I-ITOCR } & \multicolumn{3}{|c|}{ ITOCR } \\
\hline & PR & BR & CTI & PR & BR & CTI \\
\hline A & 0.1578 & 0.5055 & 0.3477 & 0.3633 & 0.7383 & 0.3750 \\
\hline B & 0.0525 & 0.5091 & 0.4566 & 0.4464 & 0.8515 & 0.4051 \\
\hline $\mathrm{C}$ & 0.0475 & 0.4450 & 0.3975 & 0.3220 & 0.6140 & 0.2920 \\
\hline $\mathrm{D}$ & 0.0667 & 0.5033 & 0.4366 & 0.3602 & 0.7355 & 0.3753 \\
\hline
\end{tabular}

\subsubsection{Evaluations of the DG Connection States}

In this case, the simulations were carried out with different DG states in the microgrid and the protection parameter settings in the different scenarios were consistent with the method of Section A. Table 12 shows the operation time of the I-ITOCRs when the fault occurs at F3 of Line 3 of the microgrid for eight scenarios; the faults are all three-phase faults, and G and I represent the grid-connected mode and islanded mode of the microgrid, respectively. As can be seen from the simulation results, 
the improved protection method is not affected by the change of DG state, and the selectivity of the relay can be guaranteed under different scenarios and different operating modes of the microgrid $(0.2<C T I<0.5)$.

Table 12. Operating times of the I-ITOCRs in the different scenarios and different operating modes of the microgrid.

\begin{tabular}{ccccc}
\hline \multirow{2}{*}{$\begin{array}{c}\text { Fault } \\
\text { Position }\end{array}$} & & \multicolumn{3}{c}{ Relay Operational Time (s) } \\
\cline { 3 - 5 } & & PR & BR & CTI \\
\hline \multirow{2}{*}{ Scenario 2 } & G & 0.0027 & 0.3772 & 0.3745 \\
& I & 0.0029 & 0.4491 & 0.4462 \\
\hline \multirow{2}{*}{ Scenario 3 } & G & 0.0117 & 0.3812 & 0.3695 \\
& I & 0.0118 & 0.4111 & 0.3993 \\
\hline \multirow{2}{*}{ Scenario 4 } & G & 0.0677 & 0.3942 & 0.3265 \\
& I & 0.0821 & 0.4617 & 0.3796 \\
\hline \multirow{2}{*}{ Scenario 5 } & G & 0.0246 & 0.3969 & 0.3723 \\
& I & 0.0235 & 0.3973 & 0.3738 \\
\hline \multirow{2}{*}{ Scenario 6 } & G & 0.0293 & 0.4304 & 0.4011 \\
& I & 0.0263 & 0.3886 & 0.3623 \\
\hline \multirow{2}{*}{ Scenario 7 } & G & 0.0093 & 0.3853 & 0.3760 \\
& I & 0.0081 & 0.3420 & 0.3339 \\
\hline \multirow{2}{*}{ Scenario 8 } & G & 0.0241 & 0.4713 & 0.4472 \\
& I & 0.0229 & 0.4590 & 0.4361 \\
\hline
\end{tabular}

\section{Conclusions}

In this paper, an improved inverse-time over-current protection method based on the compound fault acceleration factor and BAS optimization algorithm is proposed. The new method notably increases the speed of the over-current protection and improves the coordination between the adjacent relays. The potential influencing factors on ITOCR protection, including the microgrid operation modes, fault position, and fault types, were evaluated. The simulation results show that the improved inverse-time over-current protection method can quickly and coordinately remove faults under different operation modes, different fault locations, and different fault types of the microgrid, which verifies the speed and coordination of the protection method, and is better than the traditional protection methods. Furthermore, as the proposed method does not require extra devices, it is potentially more economic and easier to implement in the field, thus offering a promising solution for effective microgrid protection.

Author Contributions: Author Contributions: Conceptualization, L.J. and Z.C.; methodology, L.J. and Z.C.; software, J.S. and Z.C.; validation, L.J., Z.C. and J.S.; formal analysis, Q.H.; investigation, X.C.; resources, Y.F.; data curation, Y.M.; writing-original draft preparation, L.J. and Z.C.; writing-review and editing, L.J., Y.F. and Z.C.; visualization, Z.L.; supervision, L.J. and Z.L.; project administration, Y.F. and Y.M.; funding acquisition, Y.F. All authors have read and agreed to the published version of the manuscript.

Funding: This research received no external funding.

Conflicts of Interest: The authors declare no conflict of interest. 


\section{Nomenclature}

$\begin{array}{ll}\text { BAS } & \text { Beetle antennae search } \\ \text { DG } & \text { Distributed generation } \\ \text { TDS } & \text { Time Dial Setting } \\ \text { IIDG } & \text { Inverter-interfaced distributed generation } \\ \text { FCLs } & \text { Fault current limiters } \\ \text { HHT } & \text { Hilbert-Huang transform } \\ \text { OCR } & \text { Over-current relay } \\ \text { ITOC } & \text { Inverse-time over-current } \\ \text { ITOCR } & \text { Inverse-time over-current relay } \\ \text { CTI } & \text { Coordination time interval }\end{array}$

\section{References}

1. Liu, B.; Zhuo, F.; Zhu, Y. System operation and energy management of a renewable energy-based DC micro-grid for high penetration depth application. IEEE Trans. Smart Grid 2015, 6, 1147-1155. [CrossRef]

2. Badal, F.R.; Das, P.; Sarker, S.K. A survey on control issues in renewable energy integration and microgrid. Prot. Control Mod. Power Syst. 2019, 4, 87-113. [CrossRef]

3. Teimourzadeh, S.; Aminifar, F.; Davarpanah, M. Macroprotections for microgrids: Toward a new protection paradigm subsequent to distributed energy resource integration. IEEE Ind. Electron. Mag. 2016, 10, 6-18. [CrossRef]

4. Zhang, F.; Mu, L. New protection scheme for internal fault of multi-microgrid. Prot. Control Mod. Power Syst. 2019, 4, 159-170. [CrossRef]

5. Chen, Z.; Pei, X.; Yang, M. A novel protection scheme for inverter-interfaced microgrid (IIM) operated in islanded mode. IEEE Trans. Power Electron. 2018, 33, 7684-7697. [CrossRef]

6. Kumar, D.S.; Savier, J.S.; Biju, S.S. Micro-synchrophasor based special protection scheme for distribution system automation in a smart city. Prot. Control Mod. Power Syst. 2020, 5, 97-110. [CrossRef]

7. Hooshyar, A.; Iravani, R. Microgrid protection. Proc. IEEE 2017, 105, 1332-1353. [CrossRef]

8. Beheshtaein, S.; Cuzner, R.; Savaghebi, M. Review on microgrids protection. IET Gener. Transm. Distrib. 2019, 13, 743-759. [CrossRef]

9. Haron, A.R.; Mohamed, A.; Shareef, H. A review on protection schemes and coordination techniques in microgrid system. J. Appl. Sci. 2012, 12, 101-112. [CrossRef]

10. Fani, B.; Bisheh, H.; Sadeghkhani, I. Protection coordination scheme for distribution networks with high penetration of photovoltaic generators. IET Gener. Transm. Distrib. 2018, 12, 1802-1814. [CrossRef]

11. Belwin, J.; Raja, R. A review on issues and approaches for microgrid protection. J. Renew. Sustain. Energy Rev. 2017, 67, 988-997.

12. Soleimanisardoo, A.; Karegar, H.K.; Zeineldin, H.H. Differential frequency protection scheme based on off-nominal frequency injections for inverter-based islanded microgrids. IEEE Trans. Smart Grid 2019, 10, 2107-2114. [CrossRef]

13. Aghdam, T.S.; Karegar, H.K.; Zeineldin, H.H. Variable tripping time differential protection for microgrids considering DG stability. IEEE Trans. Smart Grid 2019, 10, 2407-2415. [CrossRef]

14. Sharma, A.; Panigrahi, B.K. Phase fault protection scheme for reliable operation of microgrids. IEEE Trans. Ind. Appl. 2018, 54, 2646-2655. [CrossRef]

15. Zanjani, M.G.; Mazlumi, K.; Kamwa, I. Application of $\mu$ PMUs for adaptive protection of over-current relays in microgrids. IET Gener. Transm. Distrib. 2018, 12, 4061-4068. [CrossRef]

16. Jain, R.; Lubkeman, D.L.; Lukic, S.M. Dynamic adaptive protection for distribution systems in grid-connected and islanded modes. IEEE Trans. Power Deliv. 2019, 34, 281-289. [CrossRef]

17. Hooshyar, A.; Iravani, R. A new directional element for microgrid protection. IEEE Trans. Smart Grid 2018, 9, 6862-6876. [CrossRef]

18. Mahamedi, B.; Zhu, J.G.; Eskandari, M. Protection of inverter-based microgrids from ground faults by an innovative directional element. IET Gener. Transm. Distrib. 2018, 12, 5918-5927. [CrossRef]

19. Huang, W.; Nengling, T.; Zheng, X. An impedance protection scheme for feeders of active distribution networks. IEEE Trans. Power Deliv. 2014, 29, 1591-1602. [CrossRef] 
20. Jin, L.; Jiang, M.; Yang, G. Fault Analysis of Microgrid and Adaptive Distance Protection Based on Complex Wavelet Transform. In Proceedings of the International Power Electronics and Application Conference and Exposition, Shanghai, China, 5-8 November 2014; pp. 1-5.

21. Muda, H.; Jena, P. Superimposed adaptive sequence current based microgrid protection: A new technique. IEEE Trans. Power Deliv. 2017, 32, 757-767. [CrossRef]

22. Mahat, P.; Chen, Z.; Bakjensen, B. A simple adaptive 0ver-current protection of distribution systems with distributed generation. IEEE Trans. Smart Grid 2011, 2, 428-437. [CrossRef]

23. Elnaily, N.; Saad, S.M.; Hussein, T. A novel constraint and non-standard characteristics for optimal over-current relays coordination to enhance microgrid protection scheme. IET Gener. Transm. Distrib. 2019, 13, 780-793. [CrossRef]

24. Najy, W.K.A.; Zeineldin, H.H.; Woon, W.L. Optimal protection coordination for microgrids with grid-connected and islanded capability. IEEE Trans. Ind. Electron. 2013, 60, 1668-1677. [CrossRef]

25. Dehghanpour, E.; Karegar, H.K.; Kheirollahi, R. Optimal coordination of directional over-current relays in microgrids by using cuckoo-linear optimization algorithm and fault current limiter. IEEE Trans. Smart Grid 2018, 9, 1365-1375. [CrossRef]

26. Kar, S.; Samantaray, S.R.; Zadeh, M.D. Data-mining model based intelligent differential microgrid protection scheme. IEEE Syst. J. 2017, 11, 1161-1169. [CrossRef]

27. Lin, H.; Sun, K.; Tan, Z.; Liu, C.; Guerrero, J.M.; Vasquez, J.C. Adaptive protection combined with machine learning for microgrids. IET Gener. Transm. Distrib. 2019, 13, 770-779. [CrossRef]

28. Mishra, M.; Rout, P.K. Detection and classification of micro-grid faults based on HHT and machine learning techniques. IET Gener. Transm. Distrib. 2018, 12, 388-397. [CrossRef]

29. Shiles, J.; Wong, E.; Rao, S. Microgrid protection: An overview of protection strategies in North American microgrid projects. In Proceedings of the IEEE Power and Energy Society General Meeting, Chicago, IL, USA, 16-20 July 2017; pp. 1-5.

30. IEC. Measuring Relays and Protection Equipment-Part 151: Functional Requirements for Over/Under Current Protection, IEC 60255-151 Edition 1.0; IEC: Geneva, Switzerland, 2009.

31. Noghabi, A.S.; Sadeh, J.; Mashhadi, H.R. Considering different network topologies in optimal overcurrent relay coordination using a hybrid GA. IEEE Trans. Power Deliv. 2009, 24, 1857-1863. [CrossRef]

32. Tjahjono, A.; Anggriawan, D.O.; Faizin, A.K.; Priyadi, A.; Pujiantara, M.; Taufik, T.; Purnomo, M.H. Adaptive modified firefly algorithm for optimal coordination of over-current relays. IET Gener. Transm. Distrib. 2017, 11, 2575-2585. [CrossRef]

33. Dahej, A.E.; Esmaeili, S.; Hojabri, H. Co-Optimization of protection coordination and power quality in microgrids using unidirectional fault current limiters. IEEE Trans. Smart Grid 2018, 9, 5080-5091. [CrossRef]

34. Sharaf, H.M.; Zeineldin, H.H.; Ibrahim, D.K. A proposed coordination strategy for meshed distribution systems with DG considering user-defined characteristics of directional in-verse time over-current relays. Int. J. Electr. Power Energy Syst. 2015, 65, 49-58. [CrossRef]

35. Jiang, X.; Li, S. BAS: Beetle antennae search algorithm for optimization problems. arXiv 2017, arXiv:1710.10724. [CrossRef]

Publisher's Note: MDPI stays neutral with regard to jurisdictional claims in published maps and institutional affiliations.

(C) 2020 by the authors. Licensee MDPI, Basel, Switzerland. This article is an open access article distributed under the terms and conditions of the Creative Commons Attribution (CC BY) license (http://creativecommons.org/licenses/by/4.0/). 